\title{
As teorias dos impulsos de Nietzsche e Freud
}

\author{
André Luís Mota Itaparica*
}

\begin{abstract}
Resumo: $\mathrm{O}$ artigo investiga as origens biológicas das teorias do impulso de Nietzsche e Freud, extraindo as consequências que delas podemos tirar. Assim, realizaremos inicialmente uma exposição das teorias dos impulsos de Freud e Nietzsche, para depois comparálas a partir das seguintes questões: (1) A gênese dos conceitos e a relação entre psicologia e biologia; (2) Os aspectos dinâmicos e econômicos dos impulsos; 3) O lugar da teoria dos impulsos no contexto de suas obras.
\end{abstract}

Palavras-chave: Trieb, psicologia, biologia.

* Universidade Federal do Recôncavo da Bahia (UFRB), Cachoeira, Bahia, Brasil. ORCID https://orcid.org/0000-0003-1344-1991

Correio eletrônico: itapa71@gmail.com 
Itaparica, A. L. M.

\section{Introdução}

Nietzsche e Freud possuem Trieblehren que se aproximam em muitos aspectos, particularmente em sua tentativa de elaborar uma psicobiologia. Mas isso não significa, necessariamente, que essa proximidade seja resultado de uma influência direta entre os dois autores, embora seja evidente que Freud conhecia mais Nietzsche do que ele mesmo admitiu. O fato é que, vivendo praticamente na mesma época, e compartilhando o mesmo ambiente cultural e científico, ambos chegaram a formulações próximas. Paul Laurent Assoun (1991) dá grande destaque aos precedentes românticos dessas teorias dos impulsos. Reinhardt Gasser (1987), por sua vez, faz uma análise minuciosa das características de cada uma delas. De nossa parte, ressaltaremos as teorias científicas sobre as quais os autores procuram sustentar sua concepção de impulso, indicando os pontos que as aproximam e as afastam. Particular atenção será dedicada a um elemento relativamente pouco lembrado (sobretudo na tradição psicanalista): as origens biológicas da noção de impulso e as consequências que delas podemos tirar. Assim, realizaremos inicialmente uma exposição das teorias dos impulsos em Freud e Nietzsche, para depois compará-las a partir das seguintes questões: (1) A gênese dos conceitos e a relação entre psicologia e biologia; (2) Os aspectos dinâmicos e econômicos dos impulsos; 3) O lugar da teoria dos impulsos no contexto de suas obras.

\section{Teoria dos impulsos em Freud e Nietzsche}

Freud afirma, em $O$ instinto e seus destinos, que o conceito de impulso é central na psicologia. Por isso, ele considera necessário oferecer um conteúdo a esse conceito que sirva de concepção basilar de sua ciência. Assim, do ponto de vista fisiológico, o impulso é uma espécie de estímulo, que segue o modelo do arco reflexo. Ou seja, o impulso é como um estímulo nervoso que provoca uma espécie de 
reação. Esse estímulo, no entanto, possui um caráter particular, já que se trata de um estímulo mental. Ele se diferencia de um estímulo fisiológico externo, como a luz que incide nos olhos: ele é interno, como nos efeitos que a sede e a fome provocam nas mucosas da faringe e do estômago. Além disso, esse estímulo mental possui um caráter dinâmico e constante, e sua resposta, ao contrário dos estímulos exógenos, dos quais se pode fugir, é sua satisfação por meio de uma alteração na fonte de excitação. $\mathrm{O}$ impulso deve ser entendido, assim, como um estímulo endógeno que age como uma força constante e que exige uma espécie particular de resposta: a satisfação instintual. Para completar essa concepção, Freud recorre ao que ele chama de um postulado e ao que ele considera uma suposição: o postulado seria o princípio de estabilidade de Fechner: a ideia de que o sistema nervoso tem por finalidade a eliminação dos estímulos ou, se isso não for possível, sua redução a níveis mínimos; a suposição é a lei biogenética de Haeckel: de que os impulsos endógenos são produto filogenético de estímulos exógenos.

É evidente que essa definição de impulso consiste num conceito de origem biológica e somática. A partir do momento em que ele é adotado para constituir uma nova espécie de psicologia, surge a questão de como, nessa teoria, deve ser entendida a relação entre o físico e o mental. A célebre resposta que Freud oferece é rica em implicações, embora não inteiramente desenvolvidas:

Voltando-nos agora para a consideração da vida psíquica do ângulo da biologia, o "instinto" nos aparece como um conceito-limite entre o somático e o psíquico, como o representante psíquico dos estímulos oriundos do interior do corpo e que atingem a alma, como uma medida do trabalho imposto à psique por sua ligação com o corpo (Freud, 2010, vol. 12, p. 57).

Essa resposta, como vemos, traz uma ambiguidade insuperável. O impulso possui uma origem fisiológica, mas terá também um correspondente mental, e por isso está no limite entre o físico e o 
Itaparica, A. L. M.

psíquico. Neste caso, o impulso é visto como um "representante psíquico" (psychischer Repräsentant) de estímulos somáticos; em outros casos, Freud menciona a existência de um representante ideativo (Vorstellungsrepräsentanz) de um impulso. Não fica claro, em ambos os casos, se Freud identificaria o próprio impulso como possuindo um aspecto físico e um mental, na forma de uma representação, ou se ele diferenciaria o impulso - enquanto propriamente físico - da sua representação, como se se tratasse, assim, de duas entidades distintas e correlatas. De qualquer modo, o que resulta aqui, pelo menos, é a ideia de um paralelismo ou uma dualidade de aspecto entre o somático e o psíquico, o que fornece uma certa autonomia do mental na descrição de suas representações, mas que o vincula necessariamente a um correlato físico.

Se essa é a definição geral do impulso, Freud esclarece em seguida suas características particulares. Antes de tudo, um impulso é sempre ativo, ele possui um ímpeto (Drang), entendido como soma de forças ou medida de trabalho físico, uma meta, sua satisfação, um objeto a que se dirige e que permite sua satisfação e a fonte de excitação de onde ele se originou. Segundo Freud, somente a fonte é exclusivamente física. Ele sublinha que ela não faz parte da psicologia, de tal sorte que ela não precisa ser identificada, embora, devemos lembrar, esteja na origem de todo e qualquer impulso. A partir desses elementos, Freud estabelecerá em sua psicologia as formas pelas quais os impulsos se organizam em termos dinâmicos e econômicos. Sendo, em última instância, uma correlação de forças entre si, seja em seu aspecto propriamente físico ou em seu correlato mental, haverá uma economia interna desses impulsos. Os impulsos, ao procurar atingir sua satisfação, podem sofrer as mais diversas vicissitudes: ser desviados contra a própria pessoa, invertidos, reprimidos ou sublimados.

Segundo a classificação dos impulsos, Freud manteve-se desde o início dualista, propondo, no entanto, duas formas de classificação.

18 | Cad. Nietzsche, Guarulhos/Porto Seguro, v.42, n.1, p. 15-30, janeiro/abril, 2021. 
Na primeira, havia a oposição entre impulsos de autoconservação, dirigidos ao próprio eu, e impulsos sexuais, dirigidos a objetos. Depois da descoberta do problema do narcisismo, quando verificou que os impulsos sexuais também poderiam ser dirigidos para o próprio eu, servindo assim para fins de autoconservação, Freud, para evitar uma concepção monista da libido, desenvolveu, em Além do princípio do prazer, um novo dualismo entre impulsos de vida e impulsos de morte, que irá permanecer até o final de sua obra, tendo um papel fundamental em suas análises sobre a cultura, como em $O$ mal-estar na civilização, por exemplo.

Segundo seu próprio relato, Freud chegou aos impulsos de morte a partir do estudo de um sintoma psicológico, a "compulsão à repetição" (Wiederholungszwang) de eventos dolorosos. Para explicar como é possível que atuem na mente representações que levam ao sofrimento, o que contradiz os princípios reguladores da vida mental, os princípio de prazer e de realidade (procurar o prazer e evitar a dor), Freud é então levado a conceber um "além do princípio do prazer": a existência de impulsos destrutivos no homem. Embora sustente que sua conclusão a respeito dos impulsos de morte tenha uma origem na reflexão psicológica, Freud recorre novamente ao princípio de constância, que passa a ser denominado de princípio de nirvana, extraindo dele uma consequência mais radical, segundo a qual a tendência de todo ser vivo seria retornar ao estado inorgânico:

$O$ fato de havermos reconhecido como tendência dominante da vida psíquica, talvez da própria vida nervosa, o esforço de diminuir, manter constante, abolir a tensão interna dos estímulos (o princípio do Nirvana, na expressão de Barbara Low), tal como se exprime no princípio do prazer - é um dos mais fortes motivos para crer na existência de instintos de morte" (Freud, vol. 14, p. 228. Tradução modificada).

Nesse texto, Freud considera o princípio de estabilidade de Fechner fundamental para compreender o princípio regulador 
Itaparica, A. L. M.

do aparato psíquico. A necessidade de satisfação dos impulsos é compreendida como uma tendência de toda a vida psíquica de permanecer como os menores níveis de excitação possíveis, dentro do mesmo esquema de compreensão dos impulsos como formas de estímulos fisiológicos. O que é acrescentado agora é a possibilidade de anular qualquer tipo de excitação, o que significaria a morte. Os impulsos de vida, agora englobando os impulsos do eu e os impulsos sexuais, seriam a contrapartida dinâmica que conservaria a existência do ser vivo.

Se entender o que significa impulso para Freud é relativamente fácil, o mesmo não se pode dizer em relação a Nietzsche, que nunca apresentou uma exposição sistemática desse conceito. $\mathrm{O}$ que podemos compreender é que, tal como Freud, Nietzsche se preocupava em entender a relação entre físico e o mental através de uma teoria dos impulsos de caráter psicofísico. Enquanto para Freud o impulso era uma forma de estímulo fisiológico com correlatos psíquicos, para Nietzsche os impulsos humanos eram uma ramificação orgânica da vontade de potência, que teria também o seu correlato psicológico (o sentimento de potência). A própria psicologia, segundo ele, deveria ser entendida como "morfologia e teoria do desenvolvimento da vontade de potência" (JGB/BM 23, KSA 5.38). Uma definição lapidar, caso houvesse também uma definição precisa do que ele entende por "vontade de potência", conceito que não aparece desenvolvido nos textos publicados, e, embora abundante nos póstumos, também ali não é desenvolvido sistematicamente.

Apesar disso, a vontade de potência é um conceito importante para compreender não só a psicologia, mas também toda a filosofia de Nietzsche (Marton 1990). Esse conceito de vontade procura não apenas se afastar de concepções racionalistas da vontade, mas também e de forma mais imediata da concepção schopenhaueriana de vontade, para Nietzsche ainda vinculada a princípios metafísicos, os quais ele procuraria superar. A tese da vontade de potência se 
apresenta como uma interpretação plausível da forma como podemos compreender a realidade se reduzirmos todos os eventos físicos à experiência de nossos afetos. Desse modo, falar de vontade de potência é antes de tudo falar de nossos impulsos; ou seja, entender a dinâmica de nossos impulsos significa identificar sua natureza e, a partir dessa compreensão, utilizá-los como fio condutor, analogamente, da interpretação da própria realidade física. Para realizar essa tentativa de redução do inorgânico e do orgânico a um conceito, que no fim das contas possui o estatuto de um princípio heurístico, Nietzsche recorrerá a concepções físicas e biológicas. Como já foi estabelecido pela pesquisa de fontes, no que diz respeito ao inorgânico, ele esposará uma concepção não-mecanicista de força, retirada dos textos de Ruggero Boscovich; no que diz respeito ao orgânico, ele se apoiará nas teorias de Wilhelm Roux e William Rolph. De Roux, ele utiliza o estudo sobre a luta entre as partes de um organismo vivo; de Rolph, a ideia de que uma característica do orgânico é sua insaciabilidade.

Quais são, então, a partir dessas fontes, as características dos impulsos humanos, enquanto uma forma da vontade de potência? Num fragmento póstumo, Nietzsche afirma que "o impulso ao poder" é "o anseio terrível e fundamental do homem" (Nachlass/FP 1[33], outono 1885/primavera de 1886, KSA 12.18). Quantidades dinâmicas como forças, impulsos e vontades são para Nietzsche sinônimos, desde que compreendamos o sentido que elas têm (GM/GM I 13, KSA 5.279). Trata-se de um apetite que não possui nenhum telos senão o aumento de sua própria intensidade. Assumindo um reducionismo para fins heurísticos, o corpo humano passa a ser considerado um conjunto desses apetites, que se apresentam psicologicamente como motivos conscientes, mas que são inconscientemente determinados, tendo como tendência não um princípio de conservação, e sim a efetivação e o incremento da força: "Contra o impulso de conservação como impulso mais radical: ao contrário, o ser vivo quer liberar (auslassen) sua força" (Nachlass/FP 26[227],verão/outono de 1884, 
Itaparica, A. L. M.

KSA 11.209). Assumindo a origem comum do orgânico e o inorgânico, seria possível, assim, reconhecendo o impulso fundamental de nossas ações, reconhecer na natureza o seu equivalente: $\mathrm{o}$ conceito de força enquanto expressão desse ímpeto por mais potência.

Assim, no âmbito físico, a vontade de potência expressa-se tanto no mundo inorgânico, como força (Kraft), quanto no orgânico, como impulso (Trieb), motivo pelo qual se pode falar do vivo como derivado do inanimado. Tomada como uma multiplicidade de forças que não possuem nenhuma finalidade senão seu próprio incremento, as vontades de potência não possuem nem qualidades nem naturezas distintas; sua relação se estabelece como um antagonismo entre forças distintas quantitativamente, cuja natureza consiste justamente na diferença entre sua força e a que a ela se opõe. Em sua economia interna, a vontade de potência pressupõe desvios, sublimações, e rearranjo de suas formas. A vontade de potência apresentase no âmbito orgânico como impulsos fisiológicos, que também terão uma expressão psicológica, mas em um registro em que se desenvolve em direção a uma "fisiopsicologia" (JGB/BM 23. KSA 5.38). Embora pareça muitas vezes flertar como um reducionismo fisicalista e eliminativista, Nietzsche reserva um lugar particular, e de destacada importância, à psicologia, não só em sua filosofia teórica, mas também nas análises propriamente psicológicas das motivações humanas, como ocorre na Genealogia da moral, em sua análise do ressentimento, por exemplo. Mas isso não deve ocultar o fato de que Nietzsche permanece sobretudo como o defensor de um projeto de naturalização da moral, que remete nossas representações mentais a esse fundo fisiológico.

O impulso é tanto um fenômeno fisiológico quanto psicológico. $\mathrm{O}$ corpo nada mais é senão um complexo de impulsos em combate constante entre si, o que pode significar formação de complexos maiores de potência ou a sua desagregação. Mas o psicológico também é produto desses impulsos, que se apresentam na forma 
de sentimentos, pensamentos e afetos. A própria vontade, tal como Nietzsche a entende, é justamente um complexo em que estão presentes a sensação muscular (Muskelgefühl) da ação a ser realizada, o pensamento dessa ação e o afeto de comando que a desencadeia (JGB/BM 19, KSA 5.32). As relações entre vontades de potência têm seus correlatos em representações mentais, sendo a expressão mental da vontade de potência mais elementar o sentimento de potência que vem a ela acompanhada, compreendido como o correspondente mental do processo através do qual as vontades de potência vencem suas resistências (GM/GM III 7, KSA 5.350).

\section{Comparação entre as Triebelehren}

Muitas são as fontes que contribuíram para a teoria dos impulsos de Nietzsche e Freud. Quanto às fontes científicas, durante muito tempo os comentários sobre Freud e Nietzsche minimizaram sua importância. Do lado de Freud, por sua insistência em compreender a psicanálise como uma teoria puramente psicológica, que se afastaria de suas considerações presentes no Projeto de uma psicologia científica, época em que sua formação de cientista natural ainda se mostrava marcante. Em nome de uma independência da psicanálise, inclusive em relação à medicina, Freud ressaltava a autonomia da psicanálise em relação às ciências naturais. Com a institucionalização da psicanálise, conduzida inicialmente pelo próprio Freud e continuada por seus seguidores, criou-se uma imagem da psicanálise afastada da biologia, imagem essa que apenas recentemente tem sido relativizada, quando não questionada. Um exemplo clássico é o livro Frank Sulloway, Freud, Biologist of the mind, no qual é mostrado como Freud permaneceu com muitos de seus pressupostos biológicos depois do Projeto, mantendo ideias que ele já compartilhava com Fliess, Fechner, Haeckel, Darwin, Lamarck e outros.

Nietzsche, por sua vez, no decorrer do século XX passou a ser reconhecido, em certas correntes de pensamento, sobretudo como 
Itaparica, A. L. M.

um filósofo da cultura e, erroneamente, como um adversário das ciências naturais. Essa visão de suas obras, no entanto, conheceu a partir da década de setenta uma mudança. As pesquisas realizadas em torno da edição crítica e dos Nietzsche-Studien retomaram os estudos sobre as fontes científicas de Nietzsche, que tinham alguma expressão na pesquisa sobre Nietzsche, no início do século XX, mas eram claramente minoritárias. Foi nesse momento que uma leitura metafísica da obra de Nietzsche passou a ser substituída por uma visão contextualizada, particularmente de sua teoria da vontade de potência. A partir daí pôde-se conhecer melhor suas leituras de obras científicas e a importância delas para a elaboração de sua teoria dos impulsos. No que diz respeito às suas fontes biológicas, o primeiro capítulo do livro de Gregory Moore, Nietzsche, biology and metaphor, fornece uma síntese do trabalho de identificação de suas fontes mais importantes, o que nos esclarece muitas das considerações de Nietzsche sobre a vontade de potência, que, sem esses esclarecimentos, nos pareceriam arbitrárias.

Em ambos os autores, encontramos também ainda um lamarckismo difuso e a crença na possibilidade de reduzir a própria biologia a fenômenos físico-químicos. Não é à toa, portanto, que tanto Nietzsche quanto Freud defendam a ideia de que há uma origem comum do orgânico e do inorgânico (que poderia ser reencontrada na noção de impulso), a concepção de que o psicológico se formou a partir de estratos anteriores e mais simples da vida orgânica e, por fim, o princípio de que a ontogenia recapitula a filogenia.

Mas enquanto Nietzsche defende com vigor uma naturalização da psicologia, Freud, embora reconhecesse uma correspondência, a ser um dia talvez confirmada, entre as descobertas da psicanálise e as ciências naturais, negava depender desses pressupostos, alegando que suas conclusões provieram do trabalho da prática analítica. O irônico dessas posições é que o naturalismo defendido por Nietzsche não procura aplicar diretamente na filosofia os resultados da ciência. Seu 
uso de teorias científicas ocorre para muitas vezes justificar os achados que se encontram, pelo menos desde seu período intermediário, presentes em análises de psicologia moral. Já Freud, por sua vez, nunca abandonou inteiramente uma concepção de aparato mental fortemente baseada em seus estudos neurológicos, como se pode atestar num dos seus últimos textos metapsicológicos, Além do princípio do prazer. Se o conceito de impulso está no centro da teoria psicanalítica, não há como negar sua base biológica, tendo como modelo o estímulo e o arco reflexo na compreensão de toda a atividade mental, que é regida pelo princípio de constância ou de nirvana, o qual, como vimos, nada mais é que uma adaptação do princípio de estabilidade de Fechner.

Apesar de aproximar por defenderem uma concepção dinâmica de impulso, compreendido como um conceito-limite entre o físico e psíquico, com o propósito de elaborar uma psicobiologia ou, como Nietzsche prefere, uma fisiopsicologia, fortemente associadas a teorias científicas contemporâneas (como a psicofísica de Fechner e a biologia de Haeckel), e por remeterem, ao fim e ao cabo, a psicologia a correlatos físico-químicos, as diferenças entre as teorias dos impulsos de Freud e Nietzsche se caracterizam por suas escolhas filosóficas. A primeira delas diz respeito à adoção de um princípio de conservação. A segunda ao modelo dualista ou pluralista dos impulsos que é adotado por cada um deles.

Variando de termo a depender da ênfase em certas nuances envolvidas, Freud nunca deixou de defender variações do princípio de estabilidade de Fechner. Seja como princípio de inércia (princípio fisiológico segundo o qual o neurônio tende a livrar-se de toda tensão provocada por excitações), princípio de constância (tendência do aparelho psíquico a minimizar a tensão pulsional a limites mínimos ou constantes) e por fim o princípio de Nirvana (tendência do aparelho psíquico de reduzir a tensão pulsional a zero), essa é uma ideia que Freud não abandona como o princípio regulador tanto do ponto 
Itaparica, A. L. M.

de vista neurológico quanto do ponto de vista psicológico. Para Nietzsche, como já vimos, a adoção de um princípio como este se contrapõe à característica central da vontade de potência, que é impor-se sempre um aumento de força (JGB/BM 13, KSA 5.27-8). Subscrever o princípio de conservação seria adotar um princípio teleológico supérfluo, já que o aumento de potência é suficiente para a compreensão dos fenômenos biológicos. O princípio de conservação seria apenas uma das consequências da vontade de potência, mais especificamente entre os mais debilitados fisiologicamente. No caso do princípio do Nirvana, denominação de herança evidentemente schopenhaueriana, Nietzsche encontraria um princípio niilista e negador da vida, ainda mais se lembrarmos que Freud chegou a formular, em Além do princípio do prazer, que o fim a que anseia tudo o que é vivo é a morte, sendo a própria autopreservação apenas um meio para atingir o retorno ao inorgânico de forma natural. Nesse aspecto, vemos uma diferença inconciliável entre as teorias dos impulsos no que diz respeito à interpretação do funcionamento do aparelho mental e nas explicações dos comportamentos humanos. Para Freud, o aparelho mental deseja evitar e eliminar as tensões que sofre, podendo, no caso de fracasso, resultar no surgimento de sintomas neuróticos. Para Nietzsche, faz parte do funcionamento psíquico a existência de tensão, resistência entre os impulsos e sua superação - não seu aniquilamento - o que produz o sentimento de potência.

A segunda grande diferença das duas teorias dos impulsos consiste na compreensão da natureza dos impulsos. Freud nega que no impulso haja qualidades intrínsecas, sendo a relação entre eles uma questão puramente quantitativa; não obstante, ele procura classificar os impulsos em tipos distintos: daí o seu primeiro dualismo, entre impulsos do eu e impulsos sexuais, e o segundo dualismo, de impulsos de vida e impulsos de morte. Não se trataria, então, de uma diferença qualitativa, mas sim, é o que podemos concluir, de 
uma diferença de natureza. Não fica esclarecido, no entanto, em que consistiriam essas naturezas distintas: podemos supor que no primeiro dualismo estaria no objeto (o eu ou um objeto externo) e no segundo dualismo na meta (alcançada por meio da agregação ou da destruição). Freud parece insistir no dualismo justamente porque ele só pode compreender o dinamismo psíquico como um antagonismo entre impulsos de naturezas distintas. Esse é um pressuposto para Freud inquestionável, embora não justificado. Para Nietzsche, ao contrário, o dualismo é uma forma de pensamento simplificador e resolutamente metafísico, que não está atento às nuances existentes tanto no plano físico quanto no psicológico. Em sua teoria, o que há é um continuum de uma multiplicidade de forças que se singularizam momentaneamente em uma relação diferencial. Não há para Nietzsche uma distinção de forças nem em termos qualitativos nem em termos substanciais: a dinâmica da vontade de potência se dá por uma diferença de quantidades em arranjos sempre momentâneos. Não há, como no segundo dualismo de Freud, impulsos agregadores e desagregadores; a vontade de potência é vista como uma força plástica que, no seu ímpeto por crescimento, possui a capacidade de tanto agregar quanto destruir, tendo em vista a ampliação de formações de domínio.

Até o momento expusemos e comparamos as duas teorias dos impulsos. Mesmo que se apoiem em estudos científicos do século XIX, elas possuem um inegável caráter especulativo. Resta saber que estatuto podemos considerar que essas teorias possuem, e que estatuto seus próprios autores reconheciam nelas. Poderíamos nos perguntar que poder explicativo e preditivo teriam teorias baseadas em teses científicas ultrapassadas, de um hoje já remoto século XIX e que só interessam a um historiador da ciência? Num texto sobre os casos clínicos relatados por Freud, Frank Sulloway afirmou, criticamente, que "má biologia resulta, no fim das contas, em má psicologia" (Sulloway 1991, p. 245). Contrariamente a essa afirmação, haveria, 
Itaparica, A. L. M.

de fato, uma independência tão grande da psicologia freudiana que ela prescindiria de seus pressupostos biológicos ultrapassados? E quanto a Nietzsche? Suas análises psicológicas seriam verdadeiras mesmo que não haja uma comprovação científica de sua teoria da vontade de potência?

Tanto Freud quanto Nietzsche, apesar do naturalismo - explícito ou não - de ambos, evitaram atribuir a suas teorias um estatuto positivo. Freud já se referiu a sua metapsicologia como uma espécie de mitologia que procura dar uma estrutura teórica provisória a seus achados clínicos. Nietzsche, de forma ainda mais explícita, designa sua teoria da vontade de potência como uma interpretação, o que pode ser entendido como uma leitura da realidade a partir de determinados valores, como uma espécie de ficção reguladora tendo em vista fins práticos. Ao mesmo tempo, seus propósitos não eram tão modestos. Nietzsche pretendia ser um médico da cultura e, diante do avanço do niilismo, prometia uma transvaloração que iria dividir a história da humanidade em duas eras; Freud humildemente recusa, em $O$ mal-estar na civilização, o papel de profeta; basta-lhe apenas ser aquele que, depois de Copérnico e Darwin, teria consumado a terceira ferida narcisista na humanidade, com a descoberta do inconsciente.

Essas autocaracterizações, no entanto, podem ser entendidas de um outro ponto de vista. Nietzsche não procurou sair do âmbito da filosofia. O que ele oferece, no máximo, é uma psicologia moral, sobre a base de uma especulação que dialoga com as ciências de sua época. Há quem considere que a teoria da vontade de potência pode ser entendida, sem grande prejuízo, como uma generalização de experiências alcançadas por meio da introspecção e da observação de motivações psicológicas. Desse outro ponto de vista, Freud teve uma pretensão maior: a de erigir um novo conhecimento científico e uma terapia que seria aplicada em doentes com enfermidades mentais muitas vezes sérias. Se em ambos os casos a teoria dos impulsos não se presta a uma verificação empírica dos impulsos propriamente 
ditos, ou mesmo sejam falseadas por evidências científicas atuais, podemos mensurar seu poder explicativo e preditivo no que diz respeito à compreensão das ações humanas. No caso de Nietzsche, em sua psicologia moral, que continua bastante apreciada; no caso de Freud, apesar de possuir uma criatividade teórica inegável e de uma perspicácia psicológica admirável, sua criação, a psicanálise, não ganhou o estatuto de cientificidade que ele almejava, sendo sua aplicação e sua eficácia clínica ainda abertas a muitas disputas. Mas mesmo com essas controvérsias, a psicanálise conquistou um lugar importante no mundo contemporâneo, dificilmente erradicável, seja como prática terapêutica ou como instrumento de análise da cultura.

\title{
The theories of the drives in Nietzsche and Freud
}

\begin{abstract}
The paper investigates the biological origins of Nietzsche's and Freud's theories of drives, drawing their consequences. First, I will expose both theories and later I will compare them, based on the following issues: (1) The genesis of the concepts and the relationship between psychology and biology; (2) The dynamical and economical aspects of drives; (3) The place of the theory of drives in the context of their oevres.
\end{abstract}

Keywords: Trieb, psychology, biology. 
Itaparica, A. L. M.

\section{Referências}

ASSOUN, P. L. Freud \& Nietzsche. Semelhanças e dessemelhanças. Tradução: Maria Lúcia Pereira. São Paulo: Brasiliense, 1991.

FREUD, S. Obras Completas. Tradução: Paulo César de Souza. Vols. 12 e 14. São Paulo: Companhia das Letras, 2010.

Psychologie des Unbewussten. In: Studienausgabe. Vol. III. Frankfurt am Main: Fischer, 1982.

GASSER, Reinhard. Nietzsche und Freud. Berlim/Nova York: de Gruyter, 1987.

MARTON, S. Das forças cósmicas aos valores humanos. São Paulo: Brasiliense, 1990.

MOORE, Gregory. Nietzsche, biology and metaphor. Cambridge: Cambridge University Press, 2009.

NIETZSCHE, F. Sämtliche Werke. Kritische Studienausgabe. Berlim/Munique: de Gruyter/dtv, 1988.

SULLOWAY, F. "Reassessing Freud's Case Histories: The Social Construction of Psychoanalysis". In: Isis, vol. 82, 1991, pp. 245-75.

. Freud, Biologist of the Mind: Beyond the Psychoanalytic Legend. Cambridge/Londres: Harvard University, 1992.

Enviado: 16/09/2020

Aceito: $26 / 10 / 2020$

30 | Cad. Nietzsche, Guarulhos/Porto Seguro, v.42, n.1, p. 15-30, janeiro/abril, 2021. 